\title{
Present problems of water management and agrarian reforms in Uzbekistan
}

\author{
Nasirjon Yusupov, Sherzod Muminov, Ilkhom Ibragimov, Boris Gojenko* \\ Scientific Information Center of Interstate Coordination Water Commission of Central Asia, Tashkent, Uzbekistan; \\ *Corresponding Author: gojbor@rambler.ru
}

Received 19 March 2012; revised 27 April 2012; accepted 6 May 2012

\begin{abstract}
The agriculture of Uzbekistan always played the important role in economy and in social life of the country. In spite of the fact that new branches of production have been created in the last years, and much higher rates the industry and service sphere were developed, the agriculture remains the one of leading directions and takes the important place in gross national product production. Its role is connected also with that it is the supplier of raw materials for quickly developing and demanded branches of light and food industry, and by that the considerable part of Uzbek population lives in rural areas and this or another ways connected with agrarian production. However, for the further development of this branch there are a number of barriers. From them the limitation of water resources and reclamation condition of the lands as well as the food security achieving are the main.
\end{abstract}

Keywords: Uzbekistan; Agriculture; Water Management; Agrarian Reforms

\section{INTRODUCTION}

The market reforms which are carried out as a whole in economy and particular in agriculture create necessary conditions for this purpose. At the same time its demand adequate transformations of water sector which to a certain extent act as the deterrent in its development. A principal basis for transition of water sector to market relations is transition to paid water use.

Creation of real conditions for establishment of market relations between agrarian sector and water management organizations is impossible without essential increasing of profitableness of farms.

The main agricultural crops of Uzbekistan are cotton and wheat. In current conditions the conjuncture of the world prices for these crops is favorable enough. Perfec- tion of the state order mechanism and purchasing prices will allow farms to realize a profit which will allow ordering economic relations between water and agricultural sectors.

\section{PRESENT PROBLEMS OF AGRICULTURE AND WATER MANAGEMENT}

Within the limits of the general strategy of development, the government of Uzbekistan has designated agriculture as one of priority directions. It connected with many circumstances. First of all the agriculture still plays the important role in a national economy, despite decreasing in gross national product last years. In 2010 its relative density has made $17.5 \%$. The basic part of the population lives in rural area and to some extent connects with agriculture. High rate of population growth is one of the highest in the CIS and in 2010 made 1.5\% demand corresponding rates of its food maintenance [1]. Here it is necessary to notice that there is a problem not only decisions of food maintenance of growing population, but also as a whole to food security of the country, the improved structures of nutrition security of the population. Present conditions of these activities are not absolutely favorable. So, according to FAO Uzbekistan has undertaken a number of measures and has reached food security which is guided on self-sufficient with a foodstuff (basically grain), but does not consider their availability, and also balancing of food for the population. Uzbekistan produces adequate calories to feed its population but more than $30 \%$ of population spends more than $60 \%$ of their income for food and consumes a diet dominated by cereals.

The fast-growing light industry of republic with its big export potential requires raw materials of high quality in escalating volumes that is possible as a result of development of the main branch of Uzbek agriculture-cotton growing. All it demands the accelerated development of agrarian sector based on irrigated agriculture more than on $80 \%$. This in turn connected with a condition and 
prospects of water management development.

Speaking about water supply we could say that one inhabitant of Uzbekistan on the average for the last five years is sharing about $2000 \mathrm{~m}^{3}$ of water, while the Earth inhabitant shares $24,000 \mathrm{~m}^{3}$. Uzbekistan is included neither into number safe nor in number of the problem countries. So water supply for one inhabitant of Uzbekistan in 1990 was $2600 \mathrm{~m}^{3}$, in 2000 was $2400 \mathrm{~m}^{3}$, in 2008 was only $1800 \mathrm{~m}^{3}$. But the situation can essentially become complicated within next years. Here the anthropogenesis reasons as urbanization; industry development; housing and communal services and natural reasons as exhaustion of glaciers feeds the basic rivers of regionAmu Darya and Syr Darya play their role. According to Sagitt Ibatullin (the Chairman of International Fund for Aral Sea Saving executive committee) in Tashkent international conference "Towards the 6th World Water Forum-cooperative actions for water security”: from 1957 to 2000 water stocks in glaciers were reduced more than on 25\%, and this process intensively proceeds. Till 2025 thousands of small glaciers will disappear, the freezing area will be reduced on $20 \%$, ice stocks will decrease for $25 \%$ [2].

There is also other reason: intention of the states located in upstream of these two rivers to use their potential in the power purposes that will lead to decrease in their irrigational possibilities. Thus, the next years the water management of Uzbekistan can appear in an extreme situation.

The decision of the arisen problems demands essentially new approach based on new mechanisms of management namely on the market relations. Extensive possibilities of development both agricultural and water sector have settled themselves, intensive methods are necessary to introduce based on market principles.

Taking into account all these we will consider some aspects of the reforms which are carried out in agrarian sector of Uzbekistan. How much they allow solving problems facing to branch, and what conditions they create for realization of market transformations in water sector?

\section{REFORMING OF AGRARIAN SECTOR AND WATER MANAGEMENT}

Reforms in agriculture have captured sphere of management of an agro complex, the organizational-legal form of farms, land use relations etc. First of all conditions for development of the family farms providing small-scale production have been created. In the early nineties for these purposes it has been allocated an order of 400 thousand hectares of irrigated land. In the subsequent instead of large ineffective collective farms the farms based on a private property have been created.

The important step was the restriction of state regulation for industrial agricultural producers' activity. Now except the cotton and a part of wheat which produces under the "state order" farmers have the right of absolutely free activity. However considering that under production of cotton and wheat the basic part of the irrigated lands is occupied, it is expedient to consider advantages and defects of the existing mechanism of their production. How much their production in conditions of market relations favorably for producers and how is possible to solve problems of rational water use through it?

Agriculture is close connected to water management in case of production and the reforms which are carried out should have the uniform logic. The well-being of water management forming of one of agricultural production major factors depends directly on the economy level of the last one. Agriculture problems which it faces in a transition period, rest against necessity of market transformations deepening, that in turn will create preconditions for their realization in water management. Proceeding from it to synchronize actions in respect of transformation of both branches, to provide the complex approach in realization of urgent questions-here that way thanks to which it is possible to reach the prompt and desirable results. That is why we will consider some basic problems of agriculture, possible ways of their decision and their influence on the decision of water management problems.

The current mechanism of the state order introduced in the mid-nineties, in disintegration of collective and formation private farms has played the positive role. Thanks to this order it was possible to provide production despite the complexities caused by shortage of circulating assets at managing subjects, presence in great volume delayed accounts receivable and account payable, rupture old and complexities of formation of new industrial communications. An appreciable role in it the "Fund for the payment for agricultural output purchased for the state needs" has played. Independently from the financial position all agricultural producers could receive advance on cotton and wheat production from the Fund, and then, handing over grown up production besides to be discharged at it. It creates certain conveniences to a commodity producer but also has some defects. The main defect among all is excessive centralization, i.e. the agricultural producer cannot at own discretion, proceeding from a concrete situation and local conditions dispose of allocated advance payment. And the second essential lack-it holds down the initiative of producer. To use to sources of Fund the producer is compelled, since it does have not enough own circulating assets, and banks do not carry out this kind of activity. At the same time the producer, being engaged in production on the state order, has low financial results that does not allow to provide the further production not involving extra means. The vicious circle turns out, and for breaking off it is extremely necessary, 
and the first step in the given direction there should be a following.

Now the state, through the authorized bodies, defines volume of production for the state order and the sizes of land occupied by crops for producers. Having kept the first and, having refused the second, it is possible to reach the following: production volumes in particular cotton, and also wheat will be provided from the smaller areas. It is most actual and real for cotton growing. On the released areas the growing of cash crops will be organized. The carried out interrogation within the limits of given research among farmers and other workers involved in agriculture, has shown support of the given idea.

It is possible to judge advantage of cash crops production on an example of the farms investigated by us. If cotton growing has provided profitability at level of $4.3 \%$, wheat of $17.9 \%$, so gardening production is about $642.1 \%$. Considering that gardening production is realized basically in cash, and for the cotton yield the farms is discharged in a current of 3 - 6 months, so it is not necessary to speak about advantages of the first. But there are also the lacks connected by that production of gardens basically perishable, and it demands a corresponding infrastructure on storage and processing, however their network is insufficiently developed in Uzbekistan [3].

Following stage in this direction should be reduction of the state order volumes. But reduction of the state order for cotton in the conditions of Uzbekistan will not mean reduction of its production. The infrastructure for cotton growing is developed enough, in comparison with other crops, and the basic part of producers at the first stages will not be interested in specialization change. Favorable conditions for industrial activity are quite comparable and competitive to high profits. But, having introduced offered model, conditions for a choice will be created, so economic freedom for the businessman will be provided that is the extremely important for market mechanism functioning.

At the same time, the processing of production besides the state order will create real preconditions for market transformations and in accompanying branches, in particular, in cotton gin and in vegetable oil branches. The cotton, in difference from wheat, does not go on personal consumption, its made part over the state order, will create possibility for farms to free choice of the processing enterprises (now such possibility is absent since every farm is attached to concrete cotton gin factory). And in turn it will create the competitive environment that will well affect industrial and economic indicators of all cycle.

Other problem connected to pricing questions. In the conditions of the state order the internal prices are much lower than the world price. This problem is a subject of many discussions. There are many points of view on the given question. Our point of view consists in the following.

Reasoning that the prices for state order production should be equal to the world prices behind a minus of the costs connected with its realization is not so correct. In that case there is a question: in what interests of the state from the production organization under its order. After all having established the order for this or that production, the state creates certain conditions for their production. It is also the financial-preferential advancing, tax and customs privileges on goods values and the services connected production for the state order and others. Creation of favorable conditions can be continued and making use of foreign experience. So, payment for water for production on the state order in China more low, than for other producers who working on the free market. The difference between world and internal price-is a financial interest of the state. In economic essence of creation of such financial interest doubts should not be [4]. But a question in that: for what these means are used? The difference between internal purchasing and the world prices for wheat creates possibility for the state to provide the population with products of its processing under more reasonable prices that is quite clear and explainable. Financial interest of the states on cotton production, formed in favorable years of conjuncture, and is spent in adverse years for supporting the producers, so that is created some kind of insurance fund. Thereby stability of production is provided. It is extremely important factor for agriculture, however as well as for other branches of economy. The factor of stability created thanks to similar insurance fund, considerably reduces market mechanism costs. Our interviewing has shown hat the stability provided thanks to the state order is adequate to high profitability for producers. But at the same time, profitability in the conditions of market relations is fatal indicator and it should be provided as a result of industrial activity. The question is about its size. If it is low and does not create a condition for simple reproduction, let alone expanded, all production loses sense. The given question for cotton growing farms of Uzbekistan is rather actual.

Other part of a difference can be used by the state in economy in whole and other spheres of a public life. Actually the majority of the countries of the world with the developed economy have passed such stage in the development when the agriculture provided the decision of nation-wide problems and it is frequent in a damage of own development. Thus, in present conditions as a whole not denying necessity for difference existence between the world and internal prices, the question costs is about its size. Having reduced a difference it is possible to receive fast effect, but thereby and possibilities of the state 
for supporting of cotton producers in adverse years also will be lowered. Here is necessary to observe both tactical and strategic interests. Thus, having improved the mechanism of the state order for cotton growing, the same volume indicators can be reached with smaller costs, so with better economic results.

Having provided sufficient interest of producer, it will be possible to solve the question of economic and financial mutual relations perfection between it and the water management organizations. These questions should dare through a prism of introduction of paid water use.

From the beginning of 2000th years water users associations (WUA) began to be created. Their basic obligetion is water delivery directly to water consumers-to farmers and to dehkan farms, and also the maintenance of an inter-farm network. The first WUA created with coverage of former collective farms territories and did not consider hydrographic features of district that has led to certain difficulties in their activity. In the subsequent, process of mass optimization of farms which took place in 2007-2009 also has created many problems in their activity. Change of structure of WUA founders and liquidation of some of them led to impossibility of collecting debts is one of these problems. The tightened process with definition of WUA status as NGO, difficult system of the taxation depending activity, also is created difficulties in their organizational formation. All it together, and the main thing-low financial indicators of farms, and also problems of financial system of agriculture became the reasons of many difficulties which continue to face WUAs. Now it is possible to assert, that process of WUAs formation goes, but goes slowly enough, and owing to available difficulties it is impossible to assume, that in the near future it will come to the end.

Today we have the right to assert, that some reserves of organizational character on transfer of a water management into market principles of management are created. But the basic condition for functioning of market relations in water sector-the payment for water-is not introduced yet.

The practice of all countries which have introduced the systems of paid water use, testifies that thanks to it the considerable economy is reached. And this economy is not only of water resources, but also labour, material, power and finally the financial resources participating in delivery of this water. Paid water use will allow to solve some other important technical problems which in the conditions of irrigation agriculture of Uzbekistan is extremely actual-even if will not improve it will promote prevention of reclamation condition of the land. The salinization soils problem is basically a problem of wrong and prodigal land use, and also water recycling. The state as the proprietor of water and land resources should provide security and effective utilization of it.
Introduction of paid water use does not mean that all expenses should lay down on balance of water consumers. The state-private mechanism of water management organization financing should become the most expedient in the conditions of Uzbekistan.

And it is necessary to change not only the form, but also the maintenance of the given process. To direct efforts to restoration of the water constructions created in the Soviet period is necessary, but taking into account the modern requirements and realities.

Creation of conditions for introduction of market mechanism of management and on its basis increase of fertility of soils that is impossible in the conditions of irrigated agriculture without maintenance of rational water use was a main objective which was pursued at formation of new land relations. In turn it demands labour, material and financial investments that is real only at the stable relations opening long-term prospect. "The Land Code" accepted in 1998 has put in pawn a basis for land transfer as state ownership in long-term rent for agrarian producers. In the beginning, term made it till 30 years, in the subsequent, pursuing the aims of maintenance of stability in ground relations that is an indispensable condition of rational and productive use of land (it is adequate also water resources), this term has been prolonged till 50 years.

Number of farms in comparison with 2006 was reduced more than in 3 times and has made 66,134, and the average plot of the earth has increased about 30 hectares to 80 hectares due to carried out optimization process. However administrative methods by which this action has been carried out had also negative consequences.

Economical use of water resources is impossible without provided its material resources. It is a question not only of availability of modern technologies and techniques. First of all it is necessary to create conditions for WUA equipment by the elementary techniques allowing to perform land works and to establish measuring devices.

Economical use of water resources in modern conditions of Uzbekistan demands certain expenses. And the state as the proprietor of water resources should not only put means in creation of material resources of rational water use but also create conditions for water consumers and stimulating to it. Here it is a question of creation of conditions both farmer and to the water management organizations and first of all WUA for acquisition and use of digging techniques and water account devices.

In present conditions of high cost of power and other resources creation of technically perfect water economic and reclamation systems will demand huge expenses whereas application of resources save technologies, working out of a rational control system by water use allows to solve a problem of an effective use of irrigating water 
and ecological safety at much smaller expenses.

So, working out and introduction of drop irrigation system discrete or underground irrigation by pressure in the conditions of Uzbekistan gets exclusively great value. Experience saved up abroad, as well as inside of Uzbekistan have convincingly proved, that at the expense of it will be possible to save about $50 \%$ of irrigation water. However the modern systems using pumping machinery and filters cost too much: from 5000 to 7000 US dollar on 1 hectare.

There are also other ways of water economy, allowing to receive good result not provided the big expenses. So, the technology of irrigation with alternation of watered and dry row-spacing allows saving to $25 \%$ of a moisture, and also-partially prevents washing off of fertilizers and, thereby providing its economy. The construction of membranes on channels, a capital lay-out with use modern is inexpensive the equipment and many other things demanding single initial certain expenses, can provide essential economy in the subsequent [5].

Essence of these requirements should consist in maintenance not extensive, but development intensive methods, as the agriculture is basic consumer of water resources, and the water management. And it means that, water management as the branch, requires serious reforms.

There are a lot of countries in the world where the problem of water supply is more sharply than in Uzbekistan. The main problem for Uzbekistan is not water supply problem, but is a problem of its rational use. This opinion of many water experts and to disagree with it is impossible. Therefore all efforts should be directed on introduction of water saving technologies, devices for water accounting, realization of measures on perfection of the account and control systems of losses providing prevention. And if efforts of the state will direct on financing of large water objects and its modernization the maintenance of divisions of average and bottom level could be carried out at the expense of participation of water consumers.

Here it is so important to provide the priority of cofinancing introductions for the high technologies demanding the big lump-sum costs. The farm especially occupied by cotton production, not in a condition to carry out this action without state support. The state, acting together with the beneficiary and the financing party solves the number of problems. First, the technology meeting economic and ecological requirements takes root. Secondly, the state, allocating in this or that size financial resources, establishing those or other rates for their using and return terms. Economic methods will provide the interests on production of that, or other crop. Thereby economic interests of the state, of a commodity producer, and also of ecological requirements will be realized.

The decision of standing problems possible only under the condition of complex approach. It is impossible to be limited here only by economic methods, even at its successful introduction. Certainly these methods are effective. But to hope only for them and to consider, that the market will place all in the places is completely incurrectly. Economic measures should be supported by serious organizational, educational and legal components. In this plan the experience of some provinces of China needy by water is interesting. At summarizing of agricultural year the important role together with economic and financial indicators is played also by an indicator of the specific expense of the water use for production of a unit of production. Formation of feeling of the careful relation to land and water resources acts as the important component of all educational work which are carried out by all organizations involved in it.

It is necessary to consider alternative sources considering, that an exit on standard expenses on water delivery taking into account consequences of under financing, problems demanding the solving, will predetermine the big loading on the country budget (even taking into account stage-by-stage input of paid water use). For today such source-the tax for water resources use is. Payers of this type of tax are all legal bodies, the individual businessmen using water for the enterprise purposes and dehkan farms. Farms considering, that they pay the single land tax which incorporates also this type of tax, are released from payment of the considered tax.

Certainly, it characterizes only one part of process. Other part is the technological process defining waterretaining capacity of processing. There are the kinds of activity consuming more considerable volumes of water and less volume. But even proceeding from a low share of the water factor in formation of cost indexes of production, its low size which as a whole does not reflect true value of a resource, does not stimulate to its economy.

There is a point of view which is applied in practice in a number of the countries, that the industrial enterprises, the raw materials for which supplies by agriculture, should participate solidary in expenses of agricultural producer, on the water management maintenance. In our opinion more essential rates of the tax for using water resources, along with the decision of other problems, will provide realization and the specified principle.

And at last, a uniting link in a chain of all listed problems the method of the integrated water resources management should act. Experience on the given question is saved up as abroad, and in Uzbekistan, as a result of realization of some pilot projects. Data of the comparative analysis of growing of basic agricultural production with the account of water use efficiency using this method are 
convincing enough. The analysis of these figures convinces of emergency of this method. Organizationaltechnical measures within the limits of the integrated control system have allowed reducing water delivery for cotton and wheat in favour of production of fruits and vegetables. At the same time the optimum mode of irrigation has allowed to raise yield and the general economy of water. Therefore the water factor estimation as regulator of economic and social development of territory and branch is necessary to connect to principle of integrated water management methods.

\section{CONCLUSIONS}

The new conceptual approach to the organization of a control system for water use should be based on intensive method of its functioning and is connected, first of all with perfection of an economic management method, as the main component of a market mechanism, optimization on this basis of mutual relations of water management organizations with agricultural producers with orientation to ecologically pure and harmless development of irrigated agriculture.

The mechanism of financing of water management organizations activity both for the budget account, and for the account of water consumers, having established a payment for water should become the basic part of an economic control system. Transition to this system will demand the certain period in which current organizing efforts of the state and farms should is directed on universal introduction of subjects of water account. Without that it is impossible to pass to effective paid water use.

The system of stimulation of rational use, protection and restoration of water resources and objects, decrease in irrevocable water consumption, the prevention of water and soils pollution should become a component of this mechanism.

Paid water use becomes the basic incentive motive for water and land saving. And a part of the public funds liberated as a result of water management organizations maintenance for the account of payment of water users, it will be expedient to direct on introduction of saving resources technologies. Realization of these projects should be based on state financing with attraction of means of beneficiaries.

Implementation of paid water use system becomes the new tool for the state on management of agriculture not by administrative, but by economic methods, as a result of use of the flexible tariff rate on water starting with crop's priority and state order presence.

Transition to paid water use and as its basic result economical use of water resources, besides set of political, socio economic and ecological problems, will solve also some technical problems-will improve a reclamation condition of lands. The state as the proprietor of water and land resources should provide safety both their effective use. And the decision of this problem through the given mechanism will be the most productive.

The process of pricing perfection is directly connected with process of state order for production, in particular regarding cotton production. As low level of profitability of cotton producing farms in present conditions, with introduction of paid water use considerably will decrease, that will make senseless from the economic point of view this production. To solve this problem, i.e. to provide not only indemnification of losses, but also to increase profitability, it is possible by perfection of the state order mechanism. Having carried out it, additional conditions for transfers both water sector and agriculture on market relations and their effective activity will be created. Having released from functions unusual for it the state will concentrate on efforts to decision of the important strategic problems of branch-on macro regulation questions.

The problem of rational water use is not only an agriculture problem. It is actual for all consumers. The industry of Uzbekistan has for today not a high indicator of water consumption, however in the long term it will grow. At the same time, participation of not agrarian spheres of economy in indemnification of expenses of the state on water delivery and in questions of its rational use through system of water taxes it is not effective enough. At present rates of the tax achievement of this problem is practically impossible, as it makes all an insignificant part in cost of production and its share is insignificant in total amount of tax assignment of enterprise. High cost of resource will induce the managing subject to its economy. And the approach from these positions should act as the dominating factor in taxation questions.

All these problems and ways of their solving should find reflexion in legislative and standard documents. In spite of the fact that in the current organic law, concerning this sphere-the "Water and water use Act" changes and additions have been brought in 2009, has ripened necessity for acceptance of new document-the "WCA Act”. The Water Code over which working out now there is begun work should become one of them. It should incorporate all experience which has been saved up in various areas of water use and water consumption last years, and also experience of the foreign countries which are carrying out successful water resources management, taking into account a role and their value for living standards of the population and the decision of country development.

\section{REFERENCES}

[1] UzSTAT. www.stat.uz 
[2] www.cenerasia.uz/newA.php

[3] Dukhovny, V.A., Yusupov, N.S., Muminov, Sh.H., Ibragimov, I.I. and Gojenko, B.V. (2011) Assessment of applicability of an equitable and sustainable financing model for agricultural water services in the agricultural sector of Uzbekistan. Scientific-Information Center of the Interstate Coordination Water Commission of the Central Asia, Tashkent.
[4] Cornish, G., Boswoth, B., Perry, C. and Burke, J. (2004) Water charging in irrigated agriculture: A analysis of international experience. FAO Water Reports, Rome.

[5] Ibragimov, I.I. (2011) Sustainable financing model for agricultural water services in the agricultural sector of Uzbekistan. The Third Expert Group Meeting on Monitoring of Investment and Results in the Water Sector in Asia and the Pacific, Bangkok, 22-23 September 2011. 